\title{
SOCIABILIDADE JUVENIL E PRÁTICAS CULTURAIS TRADICIONAIS NA CIDADE DE SÃO PAULO
}

\section{Maria Celeste Mira*}

Resumo: O objetivo deste texto é apresentar parte dos resultados da pesquisa coletiva realizada durante o ano de 2007 na PUC-SP. A investigação mapeou 18 grupos envolvidos com a recriação de culturas populares tradicionais brasileiras na cidade de São Paulo, buscando perceber as especificidades determinadas pela história da transplantação de expressões pernambucanas, maranhenses e sudestinas, bem como de quem as recriou na metrópole, muitos deles jovens e de classe média, e dos circuitos de sociabilidade, cultura e lazer pelos quais elas circulam. Tendo como base essas práticas, seus agentes e representações, o artigo desenvolve uma breve reflexão sobre os usos da "tradição" e o seu impacto na vida desses jovens.

Palavras-chave: tradição; cultura popular; juventude; cultura urbana.

\section{Introdução}

Quem vive nas capitais mais movimentadas do País, como Brasília, Rio de Janeiro, São Paulo e algumas outras, já pode ter visto uma estranha passeata: um grupo reunindo 50 jovens ou mais, tocando maracatu pelas ruas da cidade. Com suas alfaias, eles saem fazendo arrastões, como dizem, cujo objetivo não é protestar,

\footnotetext{
* Professora do Departamento de Antropologia e do Programa de Estudos Pós-Graduados em Antropologia da Pontifícia Universidade de São Paulo (PUC-SP).

Um esboço deste texto foi apresentado por mim e Luna Vargas na $26^{\mathrm{a}}$ Reunião Brasileira de Antropologia, realizada de $1^{\circ}$ e 4 de junho de 2008, em Porto Seguro, Bahia, Brasil.
} 
nem arrecadar dinheiro, nada disso. É simplesmente expressar a experiência nova e reveladora que sentem estar vivendo a partir do encontro com a "tradição". Embora os arrastões de maracatu sejam atualmente os mais comuns, não são os únicos. Nas praças e outros lugares públicos das cidades, grupos de jovens aparecem tocando, dançando e cantando, como veremos, outras expressões culturais de origem tradicional e popular.

Esse interesse de jovens urbanos por práticas consideradas tradicionais é um dos aspectos de um fenômeno mais amplo: a valorização da diversidade cultural, vale dizer, das culturas locais, regionais ou populares, num cenário de globalização oumundialização da cultura que parece ameaçar sua sobrevivência. Por isto, ao iniciar a pesquisa não consideramos que os grupos estivessem lidando com "A Tradição", mas, ao contrário, que estaríamos todos vivendo numa sociedade pós-tradicional, na expressão de Anthony Giddens (1997), ou seja, numa sociedade onde existem muitas tradições, mas nenhuma pode, ou tem cada vez mais dificuldade de se pensar como única e verdadeira.

Preferimos chamar essas práticas culturais de "tradicionais" no sentido de serem originárias ou terem tido seu auge antes do advento da indústria capitalista no país. São formas de cultura que surgiram no Brasil colonial e escravocrata, em sua maioria, criadas pelos africanos ou afro-descendentes, bem como, por vezes, também ligadas ao catolicismo de então (Del Priori, 1994; Abreu, 1999; Tinhorão, 2000; Jancsó, Kantor, 2001; Souza, 2002). Após o final do século XIX, abandonadas pelas elites, pelos brancos, pela população urbana, elas passaram a ser consideradas "populares". Têm sido também chamadas de "folclore", "cultura popular", "folguedos" ou "brincadeiras populares" e, quando têm natureza religiosa, de "catolicismo popular". Ao longo do século XX ficaram em segundo plano em relação à destacada posição da cultura veiculada pelos 
meios de comunicação de massa até que, no seu final, começaram a encontrar vários canais de escoamento. Um deles são os grupos que, em várias cidades do País, se dedicam a pesquisar e recriar as agora denominadas culturas tradicionais.

Na cidade de São Paulo, no ano de 2005, era razoavelmente grande o seu número. Na lista de contatos do antropólogo e produtor cultural Marcelo Manzatti, que serviu de ponto de partida para a pesquisa, havia 38 grupos. No início de 2007, ao checarmos a lista para começar a pesquisa, constatamos que 14 grupos já estavam inativos ou haviam se fundido com outros, indicando, já de início, sua instabilidade ou um certo refluxo da onda de recriação de culturas populares tradicionais na cidade. Restavam, portanto, 24 grupos em atividade. Trabalhos anteriormente realizados em São Paulo (Taboada, 2000; Munhoz, 2002; Mira, 2006) evidenciaram a participação decisiva de jovens de classe média, estudantes universitários ou do $2^{\circ}$ grau, não apenas como público das festas e eventos do circuito, mas também da própria sustentação dos grupos e ONGs que as realizavam. Porém, esses estudos haviam sido elaborados tendo como base apenas três grupos que chamaremos aqui de pioneiros: o Abaçaí, cujas origens remontam a 1973, o Cupuaçu, criado em 1986, e o Cachuera, de 1988. Nosso problema de pesquisa, que acabou dando título ao projeto, era o seguinte: seriam as conclusões desses trabalhos, notadamente em relação ao perfil dos integrantes, válidas para os grupos menores, menos conhecidos e mais recentes? Em outras palavras, seriam os demais grupos igualmente formados por jovens, predominantemente de classe média?

Foi tentando responder a essa questão, e procurando conhecer um pouco mais as práticas culturais tradicionais na cidade, que empreendemos esta investigação. Para iniciá-la, entramos em contato com o Fórum Permanente para as Culturas Populares de São Paulo que convocou uma reunião plenária na qual estavam presentes 
vários líderes de grupos. Em seguida, já inteirados da pesquisa, os líderes receberam questionários enviados pela internet com questões sobre o seu perfil e o de seus grupos. Dezoito foram respondidos. Numa segunda fase, visitamos os grupos, em seus locais de ensaio, observando, entrevistando os líderes, fundadores ou membros mais antigos e aplicando questionários aos integrantes. No total, obtivemos 17 entrevistas e 165 questionários.

As alunas de iniciação científica compareceram também a algumas festas, eventos culturais e apresentações dos grupos, observando os frequentadores a partir do método antropológico da observação participante, visando complementar o que denominamos de espaços de sociabilidade, segundo a definição de Georg Simmel, ou seja, aquele sentimento que, numa interação entre indivíduos extrapola os impulsos ou interesses que lhe deram origem ou as finalidades às quais se destina. A sociabiabilidade seria, assim, a satisfação gerada por estar em sociedade independentemente do conteúdo da interação, a relação social pura, a forma lúdica da sociação (Simmel, 2006, p. 65). Presente em toda e qualquer relação social, este aspecto, a sociabilidade, é importante demais para os jovens. Mais complexo, no entanto, foi definir os limites dessa faixa etária que, inventada na modernidade (Passerini, 1996), tende a estender-se indefinidamente, encurtando a infância e adiando a velhice (Morin, 1975). Delimitamos, para os efeitos da pesquisa, a faixa dos 18 aos 25 anos como a que separava a juventude da adolescência e da idade adulta, embora entendêssemos que uma espécie de estilo de vida juvenil pudesse se prolongar indefinidamente.

Finalmente, a opção pelo termo "recriadores": é porque os grupos pesquisados são chamados assim pelo Fórum Permanente para as Culturas Populares de São Paulo, tendo este, inclusive, criado uma comissão específica visando à sua organização. Nos nossos debates teóricos decidimos adotar esta denominação para diferenciar os grupos que estávamos pesquisando daqueles, ainda 
hoje, considerados tradicionais, por exemplo, o Maracatu Nação de Recife. Embora a polêmica seja grande a respeito desses grupos, com certeza, os novos grupos envolvidos com essas práticas nas grandes cidades não são tradicionais em nenhum sentido do termo, o que não significa dizer, por outro lado, que algum dia houve uma versão autêntica ou pura que foi corrompida ou descaracterizada. Toda e qualquer cultura é sempre e, ao mesmo tempo, autêntica e recriada, especialmente a que chamamos de popular, fortemente apoiada na oralidade. A cultura oral é recriada a cada vez que é interpretada, e isto significa que ela muda constantemente. Mesmo os grupos que, muitas vezes, nós, antropólogos, consideramos tradicionais estão em constante mudança.

\section{Os grupos recriadores e suas principais características}

Os grupos recriadores não são bandas ou conjuntos de música, embora possam ter origem neste universo. Música, bem entendido, com forte ênfase na percussão. Quando se decidem por este caminho fogem à categoria aqui delineada. Configuram algo que já é comum na música popular brasileira: um conjunto musical que se inspira em tradições populares para elaborar suas canções e construir uma carreira artística convencional. Embora quase nunca sejam profissionais, os grupos recriadores fazem apresentações de rua e de palco e parecem ter criado um novo padrão. Assim como existem duplas, trios, bandas, orquestras, cada qual com o seu número de componentes, os recriadores de cultura popular tem por volta de 14 a 16 elementos, número suficiente para que toquem, cantem, dancem, declamem, pulem, saltem, ocupando todo o palco. Diferentemente de um conjunto convencional, sua apresentação envolve várias linguagens, entre as quais a música, a dança, e, por vezes, também o teatro e o circo.

$\mathrm{Na}$ verdade, essa é uma tendência importante dos grupos envolvidos com culturas populares na virada do milênio: a de 
misturar essas várias linguagens que, na esfera culta, em geral, encontram-se separadas. Consideram que no espaço das culturas populares todas essas linguagens são aspectos de uma única manifestação e procuram manter a integração entre elas. Alguns deles estão às voltas com o que Mário de Andrade (1982) reuniu sob o título de danças dramáticas do Brasil, como os congos, o maracatu, o bumba meu boi do Maranhão e o de Pernambuco, mais conhecido como cavalo marinho. Mas há várias outras expressões populares representadas por esses grupos, sendo as mais frequentes: o coco, o cacuriá, o tambor de crioula, caboclinhos, ciranda, samba de roda, jongo e batuque de umbigada.

Os recriadores não são grupos profissionais. Em alguns casos, a profissionalização aconteceu, mas, de modo geral, no início, era só brincadeira, um grupo de amigos. Em outros casos, ainda, o grupo se divide quanto ao caminho a seguir, o que acaba gerando uma crise interna e, por vezes, sua dissolução ou reformulação. Por fim, em boa parte dos casos, não é isto o que interessa: mas o culto à tradição, o contato com os mestres e as "comunidades" - como eles se referem aos artistas populares - e, entre os mais jovens, sobretudo, a música, a dança e a percussão.

Em função disso, os grupos têm um nível muito baixo de formalização. Tanto que um dos objetivos do Fórum Permanente para as Culturas Populares de São Paulo foi o de ser um ponto de referência para sua reunião e organização. Os mais antigos e bemsucedidos fogem a essa regra: o Abaçaí Cultura e Arte é hoje uma OSCIP (organização da sociedade civil de interesse público), a qual, pelo processo de terceirização, gerencia quase toda a atividade cultural do Estado de São Paulo. A Associação Cultural Cachuera é uma organização não-governamental com atividades culturais em vários setores. Ambas superaram, em muito, o grupo de danças que um dia lhes deu destaque. Os mais profissionalizados são também mais formalizados: o Cupuaçu tomou a forma de uma sociedade 
civil sem fins lucrativos, a Cia. de Artes do Baque Bolado e o grupo Babado de Chita possuem registro na Cooperativa Paulista de Teatro. Como veremos adiante, por ser um projeto social ligado oficialmente a uma instituição, o grupo Ilê Aláfia também se tornou uma ONG. Todos os demais não têm nenhum registro, são totalmente informais.

Exceto o Cachuera, cujo diretor é proprietário do imóvel onde está situado, e o Cupuaçu, que conseguiu um local para se instalar, nenhum outro tem sede própria. Os locais de ensaio são variados e sempre provisórios: na casa do líder ou de outro integrante do grupo; em locais cedidos pela prefeitura, como as casas de cultura, quadras de escolas ou, o que é muito comum, nas praças públicas, na Cidade Universitária, como se denomina o Campus da USP etc. A falta de uma sede própria, ao lado da carência de recursos financeiros foi apontada na pesquisa como a principal dificuldade que os pequenos grupos enfrentam. Isto tem relação com a maneira como muitos se estruturam, nesta ambiguidade entre ser um grupo de amigos ou um conjunto profissional. A pesquisa revelou também que os pequenos grupos praticamente não recorrem a leis de incentivo à cultura nem aos editais de financiamento do governo federal, como o Programa Cultura Viva, tendendo a permanecer, assim, na informalidade.

Outra característica marcante dos grupos recriadores é a sua postura de ocupação do espaço urbano. Além de ensaiar em praças e lugares públicos da cidade, eles saem de suas sedes e locais de ensaio quando são fechados, tocando os tambores, dançando, cantando, em forma de cortejo, sob o olhar admirado dos transeuntes. Neste caso, a formação é maior, variando de 30 a 100 pessoas. São oficinas abertas, projetos sociais, grupos maiores, ocasiões festivas em grupos menores, encontros de vários grupos, recriação de uma festa popular tradicional etc. Circula no meio a ideia de que o lugar da cultura popular é a rua, de modo que eles se apresentam muito em festas populares tradicionais, em ruas, praças e 
parques, espaços abertos, fora do palco, de pé no chão. Numa atitude totalmente contemporânea, aproveitam características das culturas populares tradicionais para fazer sua intervenção no espaço urbano, sua performance, da mesma forma que alguns artistas plásticos se propuseram a levar sua arte dos museus para as ruas da cidade.

Não têm sede, mas têm site. A maioria se ancora num lugar virtual, no qual o grupo pode ser encontrado, contatado para apresentações e até um pouco conhecido através de textos, som, fotografias e imagens em vídeo no próprio site ou através de um link que remete o visitante para o youtube. É bem verdade que os grupos mais profissionalizados são os que tem sites bem elaborados com suas agendas de apresentação atualizadas. Mas, no geral, mesmo que seja apenas através de listas de e-mail, a Internet é o principal meio de comunicação entre eles e praticamente o único veículo de divulgação do seu trabalho, além do chamado "boca a boca". Novamente, os mais profissionais tem folders do grupo e distribuem flyers para divulgar suas apresentações. Embora isto represente muito pouco em termos da oferta de espetáculos numa cidade como São Paulo e, como vimos, a profissionalização não seja o objetivo de muitos grupos, vale a pena examinar um pouco melhor como eles foram crescendo na cidade.

\section{A onda de recriação de culturas populares tradicionais na virada do milênio}

Dentre os grupos recriadores de culturas populares tradicionais em São Paulo pode-se reconhecer, com algumas exceções, três linhagens: a que desenvolve expressões maranhenses, o conjunto dos grupos de influência pernambucana, principalmente do maracatu, e os que se apóiam nas manifestações do sudeste. Todas elas se desenvolveram tendo como base um dos grupos pioneiros: o núcleo maranhense expandiu-se a partir da criação do grupo Cupuaçu; o 
sudestino surgiu como desdobramento das pesquisas do Cachuera; e os recriadores de maracatu vêm da Cia. de Artes do Baque Bolado, a qual, por sua vez, foi iniciada nesta tradição pernambucana por integrantes do Abaçaí Cultura e Arte. Até o final dos anos 90 eram basicamente esses quatro que atuavam na cidade. Entre 1999 e 2002 surge uma nova série de grupos voltados para a recriação de práticas culturais tradicionais populares. Alguns motivos dessa nova onda são a própria repercussão e o desdobramento dos primeiros grupos, com o consequente aumento da oferta de cursos, oficinas e outros espaços de sociabilidade e lazer em torno da cultura popular tradicional.

Porém, trata-se, sobretudo, de um momento muito propício para o seu florescimento em nível nacional: as comemorações dos 500 anos do descobrimento do Brasil. Em São Paulo, além de outros efeitos, as exposições realizadas no Parque do Ibirapuera atraíram muitos estudantes para esse universo cultural e, como a construção da nacionalidade está fortemente vinculada à ideia de folclore e cultura popular (Ortiz, 1992), políticas de incentivo se tornaram mais frequentes. No caso específico dos grupos recriadores de culturas populares serão importantes os espaços e as atividades possibilitadas pelas casas de cultura e pelos Centros Educacionais Unificados (CEUs) e o incentivo financeiro do Programa para a Valorização das Iniciativas Culturais (VAI), todos criados pela Prefeitura Municipal de São Paulo em gestões do Partido dos Trabalhadores. Talvez pela proximidade, os pequenos grupos recorrem mais aos editais municipais.

As três linhagens começam a crescer, mesmo a menor delas: a sudestina. Em 1998, no interior do Cachuera, forma-se o Cambaiá, praticante do moçambique de bastão. No ano seguinte, o Zabandá traz o congo do Espírito Santo para as praças de São Paulo. Em 2002 tem início o Sambaqui, grupo de samba de bumbo. Na linhagem maranhense - que antes do final da década já havia gerado grupos como Companhia de Artes Tambores e Tambor do Querô, ambos 
dedicados ao tambor de crioula, o Boizinho de Cofo, praticante do boi de zabumba e coco caroço -, surge, em 2000, o Pé no Terreiro, dançando principalmente o cacuriá. Os grupos de maracatu se multiplicam ainda mais. Na trilha do Baque Bolado, formado em 1996, surgem, em 1999, o Batuntã, misturando o maracatu e outras tradições populares com a musicalidade urbana e contemporânea, e o Ilê Aláfia, na intenção de ser fiel à tradição do maracatu de corte real. Em 2001, tem início o Projeto Calo na Mão que dará origem aos grupos Viralatisse (2002) e Bloco de Pedra (2005). Em 2002, aparece o grupo Caranguejeira e, em 2003, a Cia. Caracaxá. Ainda em 2002, das oficinas das casas de cultura saem dois grupos que não se enquadram exatamente nas três linhagens: na Penha, o Beija Fulô, mais voltado para a recriação de cantos de trabalho, embora um de seus fundadores e integrantes, até hoje, seja Téo Menezes, do núcleo maranhense; e na Lapa, o Babado de Chita, um grupo mais independente e praticante de várias expressões.

Esse momento favorável gerou na cidade um circuito que estrutura práticas de sociabilidade, consumo e lazer por onde transita um público de classe média interessado em culturas tradicionais (Mira, 2006). Além disto, formou-se um pequeno nicho de mercado constituído, sobretudo, por apresentações pagas. O principal espaço a ser conquistado pelos grupos interessados é a Rede Sesc, em especial as unidades situadas nos bairros de classe média de Pompéia e Pinheiros, as mais voltadas para as culturas populares tradicionais. Somente os grupos que seguiram o caminho da profissionalização conseguem se apresentar com mais assiduidade na instituição. Outros locais de apresentação são os espaços ligados à prefeitura municipal, como a Galeria Olido, o Centro Cultural São Paulo, as casas de cultura, como o Tendal da Lapa, escolas particulares, empresas, teatros, bares e casas de show.

O Sesc é a instituição que remunera melhor os grupos, cerca de $\mathrm{R} \$ 3.000,00$ por apresentação, valor este que dividido pelo 
número médio de participantes não chega a $\mathrm{R} \$ 200,00$ para cada um. Ou seja, mesmo os integrantes dos grupos mais profissionalizados não conseguem sobreviver dessa atividade. Ao contrário, muitas vezes, os cachês ficam para o sustento do grupo e mais doações ainda tem que ser feitas por seus membros ou líderes para tornálo viável financeiramente. Praticamente todos os componentes têm outros trabalhos, mas quanto mais se profissionalizam, mais as atividades fora do grupo tendem a ter relação com o que se faz nele. Nos grupos mais profissionais, os integrantes são artistas, particularmente músicos ou dançarinos, produtores culturais etc. Mas outro mercado de trabalho ao qual estão particularmente ligados é o da arte-educação. Vários participantes de grupos recriadores complementam sua renda dando aulas ou ministrando oficinas de dança, canto, música, percussão, práticas corporais, artes circenses etc. $\mathrm{O}$ mercado de trabalho para os arte-educadores que, aliás, também tem atraído pessoas para participar dos grupos, é constituído pela demanda de escolas particulares que abriram espaço para as culturas tradicionais no próprio currículo ou em atividades extra-curriculares; por órgãos governamentais, ONGs ou empresas privadas para desenvolver seus projetos socioculturais; e por escolas especializadas como, por exemplo, o Brincante criado por Antonio Nóbrega e Rosane Almeida, em 1995, ou a Escola Prego Batido, aberta em Perdizes por Eder Rocha, de quem falaremos logo mais. $\mathrm{O}$ fato de ambos serem pernambucanos não é mera coincidência. $\mathrm{Na}$ virada do milênio, a voga de recriação de culturas populares em São Paulo tem uma presença muito forte de ritmos, personagens, instituições e movimentos de Recife.

\section{A localização dos grupos recriadores no bairro alternativo da Vila Madalena}

Numa metrópole como São Paulo, não se pode ter notícia de tudo o que está acontecendo. Principalmente nas periferias da 
cidade, é provável que existam mais grupos trabalhando com tradições populares, sobretudo em projetos sociais. Afinal, isto tem acontecido no Rio de Janeiro, em Salvador e outras cidades há tanto tempo que já se tornou um modelo. Feita esta ressalva, nossa pesquisa confirmou o que os trabalhos anteriores já haviam levantado: a forte concentração dos grupos envolvidos com recriação de cultura popular tradicional numa parte da Zona Oeste da cidade que pode ser caracterizada como de classe média alta mais do ponto de vista cultural do que do ponto de vista econômico. A região conta com boas universidades, uma forte concentração de escolas consideradas alternativas, ou seja, baseadas no método construtivista, surgidas desde os anos 70, uma série de equipamentos culturais com opções de programação não convencionais, como o Memorial da América Latina, o Sesc Pompéia etc. Nessa região da Zona Oeste situam-se os locais de ensaio de quase todos os grupos encontrados: Babado de Chita, Baque Bolado, Batuntã, Bloco de Pedra, Cambaiá, Cia. Caracaxá, Pé no Terreiro, Sambaqui, Viralatisse e Zabandá, cujas histórias serão contadas brevemente no próximo item.

Além disso, outros fatores podem explicar essa concentração. O primeiro deles é a localização nessa região do que chamamos aqui de grupos pioneiros. Uma das maiores evidências da pesquisa foi a de que, para os grupos menores e mais recentes, há alguns que se tornaram referência. O Abaçaí, o Cachuera e o Cupuaçu: são lugares onde os grupos menos conhecidos descobriram a cultura popular tradicional, dos quais já participaram ou nos quais fizeram cursos e oficinas, onde hoje pesquisam, se apresentam, frequentam, encontram abrigo, indicam para outras pessoas, etc. Do bairro da Água Branca ao do Butantã, os grupos pioneiros se situam em trechos próximos, praticamente contíguos da Zona Oeste da cidade.

O Abaçaí Cultura e Arte se reúne no Parque da Água Branca, a Associação Cultural Cachuera fica na Rua Monte Alegre, a meio quarteirão da PUC de São Paulo, em Perdizes, e o grupo Cupuaçu, no 
Butantã, próximo à USP. O fato de, na mesma região, aparecerem as duas universidades de maior prestígio da cidade também é relevante. Essa movimentação em torno da cultura popular tradicional está muito ligada aos universitários, muitos estudantes e alguns professores, principalmente da USP, lugar onde nasceu o Cachuera e outros grupos depois dele. Só a localização desses pontos de referência muito fortes explica, em grande parte, a estruturação do circuito da cultura popular tradicional em São Paulo, formando, na expressão de José Guilherme Magnani (2000), uma mancha que vai dos bairros da Água Branca ao do Butantã, passando por Perdizes, Pompéia e Vila Madalena.

O bairro da Vila Madalena é o centro da mancha, o ponto de maior concentração de grupos, escolas de dança e percussão, espaços para festas e eventos etc. Não é por acaso. A Vila Madalena tem abrigado, desde os anos 70, diversos movimentos alternativos, como a própria imprensa alternativa, a produção independente de música, o novo cinema paulistano. Desde os anos 60 é um bairro habitado por artistas, intelectuais e estudantes, vários deles migrantes, principalmente da Região Nordeste do Brasil (Squeff, 2002). Também foi na Vila Madalena que teve início a recriação de maracatu em São Paulo com o antigo Maracatu do Baque Bolado, hoje Cia. de Artes do Baque Bolado. Surgido em 1996, o grupo foi o primeiro a fazer uma leitura paulistana do maracatu. Com instrumentos de samba e uma batida meio diferente, começou a fazer arrastões pela Vila e a despertar a atenção dos frequentadores do bairro para o ritmo pernambucano.

\section{Os jovens paulistanos e a recriação de maracatu}

Vários grupos recriadores de maracatu e de culturas populares tradicionais em geral se inspiraram no Baque Bolado, porque ele foi o mais bem-sucedido nessa leitura contemporânea. A companhia, já 
com 12 anos, integra canto, dança, percussão, teatro e circo. Muitos integrantes de outros grupos atuaram ou atuam lá, de modo que o grupo se tornou também uma escola, sobretudo de maracatu. No entanto, os próprios líderes dos grupos acreditam que a proliferação da tradição pernambucana - não restrita à capital paulista, mas atingindo o interior e outros Estados -, deveu-se à explosão do movimento Mangue Beat. Não do movimento, em toda a sua complexidade, mas da divulgação espetacular do maracatu, ou melhor, da sua fusão embora quase irreconhecível - com a música eletrônica. Através do Mangue Beat, os jovens das grandes cidades passaram a conhecer o maracatu em sua própria linguagem audiovisual. Em outras palavras, o Movimento Mangue Beat atuou como um mediador entre essa prática cultural tradicional e a experiência juvenil urbana.

Porém, mais decisiva do que o próprio movimento, foi a vinda de vários músicos pernambucanos para São Paulo naquela ocasião - desde o próprio Chico Science até a banda Mestre Ambrósio que passou a residir na capital e a fazer shows na Vila Madalena. Ali, onde já funcionava o Teatro Escola Brincante desde 1995, com aulas de danças brasileiras, onde o grupo Baque Bolado já fazia seus arrastões desde 1996, surge o personagem que mudaria o rumo da história dos recriadores de maracatu. Integrante da banda Mestre Ambrósio, Eder Rocha começa a ministrar oficinas de maracatu em 1998, de certa forma, corrigindo o sotaque paulistano do grupo Baque Bolado. Com a autoridade de quem vivenciou a tradição, de quem conhece o maracatu nação, ele passou a dar aulas a centenas de interessados, no espaço da Cia. Cênica Nau de Ícaros, na Vila Madalena. O movimento se alastrou e os grupos se multiplicaram, sobretudo naquele trecho da Zona Oeste da cidade. Hélder Vasconcelos, outro integrante da banda Mestre Ambrósio, foi dar aulas de cavalo marinho no Teatro Escola Brincante, cujos cursos de danças brasileiras foram atraindo cada vez mais jovens, principalmente os de classe média. Mais tarde, Antonio Nóbrega e 
Rosane Almeida fariam uma série de televisão para o Canal Futura, da Rede Globo, com este título: Danças brasileiras.

Fora da mancha, há poucos grupos, fato confirmado pelos próprios líderes e integrantes, constantemente questionados sobre isto. Um bom exemplo é o Ilê Aláfia, um recriador de maracatu, pioneiro, segundo Lelo Morais e Rafael Rocha, em levar essa expressão para fora da cena cult, ou seja, para os bairros do Jabaquara e Vila Clara, uma região da periferia da cidade. $\mathrm{O}$ grupo foi criado pela educadora Maria da Conceição Santos e esses dois alunos que frequentavam suas aulas, os quais hoje são, respectivamente, a líder e os coordenadores da percussão jovem. O Ilê Aláfia está vinculado a uma instituição filantrópica, o Centro de Desenvolvimento Comunitário Leide das Neves, mantido pela Associação Cristã de Moços (ACM) de São Paulo. Seus aproximadamente 80 integrantes fazem parte de um projeto sociocultural dirigido a crianças, adolescentes e jovens, sendo que dois dos responsáveis são educadores da instituição durante a semana e um tem outra profissão. Para todos, o trabalho com o grupo é voluntário.

No interior da mancha da cultura popular tradicional apenas um dos novos grupos é fruto de um projeto social, o Bloco de Pedra, também praticante de maracatu. De acordo com o depoimento de Luis Gustavo Pinto de Moraes, seu atual líder, o grupo, depois denominado Projeto Calo na Mão, começou em 2001 como tentativa de solucionar os problemas de violência e depredação das instalações pelos quais passava o Colégio Alves Cruz, próximo à Vila Madalena. Com o apoio do Projeto Aprendiz, tiveram início as aulas e oficinas de percussão e maracatu. Mais tarde, com recursos da Petrobrás, vieram também as oficinas de construção de instrumentos que reúnem cerca de uma centena de jovens para a prática do maracatu na quadra da escola aos sábados à tarde.

No mesmo horário, os jovens do Ilê Aláfia estão ensaiando no bairro do Jabaquara. Tocam, dançam e entoam as loas do maracatu 
com a mesma animação. Mas, evidentemente, são diferentes. Conforme vão se afastando dos bairros mais centrais, além de se tornarem mais raros, os grupos recriadores, como era de se esperar, vão mudando sua composição socioeconômica. Uma comparação entre o perfil dos integrantes do Ilê Aláfia e o dos grupos Bloco de Pedra e Cia. Caracaxá pode ser reveladora. No Ilê Aláfia, dentre os que estão no grupo há mais de um ano, cerca de um terço se declararam negros, um terço pardos ou mestiços e um terço brancos. Por volta de $75 \%$ nasceram naquele bairro e os outros $25 \%$ são migrantes. Cerca de metade do total é filho de migrantes, dos quais $64 \%$ vieram da região Nordeste do país. O nível de escolaridade varia, em geral, do $1^{\circ}$ grau incompleto ao $2^{\circ}$ grau completo, atingindo a faixa dos $89 \%$; quanto ao $3^{\circ}$ grau, $7 \%$ iniciaram, mas não completaram a faculdade e apenas 4\% concluíram. Em grande parte, isto se deve ao fato de a faixa etária dos integrantes ser mais baixa, em média de 19 anos, estando muitos deles ainda cursando o ensino fundamental. Porém, de fato, apenas $39 \%$ do grupo é formado por estudantes, contra $61 \%$ de não estudantes. As profissões mencionadas revelam que muitos não puderam estudar: eles são ajudantes, atendentes, agentes administrativos, etc. Excetuando-se a líder e os coordenadores de percussão, apenas um integrante é educador e outra, a única pessoa com curso superior completo, fez a faculdade de artes e é arteeducadora, caso bem mais comum nos grupos situados no interior da mancha.

O contraste é nítido quando comparamos o perfil desses jovens com o dos que participam de grupos semelhantes na Zona Oeste da cidade, como o Bloco de Pedra e a Cia. Caracaxá, oficinas abertas que ensaiam, respectivamente, no Colégio Alves Cruz, localizado próximo à Vila Madalena, e na Praça do Relógio na USP, e pelas quais vários integrantes circulam. ${ }^{1}$ A maioria absoluta, $70 \%$, declarou-se de cor/etnia branca, 9\% negra, 6\% parda, 3\% branca/ indígena e $12 \%$ não responderam. Grande parte do grupo que 
respondeu ao questionário também era formada por paulistanos, nada menos do que $76 \%$, os quais, somados a mais $6 \%$ nascidos na Grande São Paulo chegavam a $82 \%$. Os outros $18 \%$ vinham: $3 \%$ do interior de São Paulo e 15\% dos Estados do Paraná, Santa Catarina e Rio de Janeiro. Paulistanos, filhos de paulistanos somam $33 \%$ contra $12 \%$ de filhos de paulistas; $33 \%$ cujos pais nasceram nas Regiões Sul ou Sudeste, 15\% que têm pelo menos um dos pais nascidos na Região Nordeste e, finalmente, 6\% que são filhos de estrangeiros. O nível de escolaridade também é superior ao dos jovens do Ilê Aláfia, em parte devido ao fato de a média de idade ser maior, girando em torno dos 22,6 e variando de 16 a 29 anos. Porém, os outros indicadores de classe permitem perceber que não se trata apenas disto. Grande parte dos integrantes desses grupos é formada por estudantes universitários, cerca de $36 \%$ dos que responderam ao questionário, contra $24 \%$ já graduados, $18 \%$ de estudantes do $2^{\circ}$ grau ou de escolas de música e $18 \%$ de não estudantes; apenas $4 \%$ não responderam.

Todos esses números indicam claramente a diferença de classe entre os grupos que estão recriando maracatu no interior da mancha da cultura popular e fora dela. O Bloco de Pedra e a Cia. Caracaxá são apenas dois grupos e representam um perfil médio dos demais, embora não retratem as especificidades de cada um. O nível cultural de um grupo como o Batuntã é maior ainda. Confirmando as pesquisas anteriores, os integrantes dos grupos recriadores de maracatu são jovens de classe média, estudantes do $2^{\circ}$ grau, universitários ou já graduados, predominantemente da área de Ciências Humanas e Artes. Foi entre eles que encontramos o fenômeno propriamente juvenil de interesse pelas culturas populares tradicionais no ano de 2007. Nos núcleos maranhense e sudestino, a faixa etária é mais alta.

Se os grupos estão concentrados nesta região da cidade significa que essa atividade de recriação e tudo o que ela implica, ou seja, a 
seleção, a interpretação e a reorganização dos elementos tradicionais (Halbwacks, 1990; Bastide, 1971; Williams, 1980) está nas mãos desta fração de classe, com seus respectivos capitais econômicos e culturais (Bourdieu, 1989). Um fato muito esclarecedor sobre esta nova geração de recriadores de maracatu e outras práticas da cultura popular tradicional - o que também concorre para a sua concentração na Zona Oeste da cidade - é a sua passagem por estabelecimentos de ensino considerados alternativos que vão desde o infantil até o $2^{\circ}$ grau como, por exemplo, Fralda Molhada, Escola da Vila, Equipe, Logus, Oswald de Andrade, Caravelas, hoje Oswald/Caravelas, local onde ensaia o grupo Babado de Chita. É bem o caso do grupo Batuntã, formado, em 1999, por alunos do $2^{\circ}$ grau dos colégios Equipe e Logus. Essas e outras escolas são particulares e recebem um público de classe média, cujos pais investem no capital cultural de seus filhos, mas trata-se de um capital cultural diferenciado, voltado para as Ciências Humanas e as Artes, que tem formado artistas e público jovem para esta e outras movimentações musicais importantes de que tem sido palco o bairro boêmio da Vila Madalena.

Porém, algo aproxima todos esses jovens, os de classe média e os mais pobres: o fato de se identificarem com práticas culturais até então totalmente desconhecidas para eles, que não tinham nada a ver com a sua experiência de vida anterior. $\mathrm{O}$ fato de haver entre os jovens do Ilê Aláfia mais filhos de migrantes, boa parte nordestinos, alguns pernambucanos, não os aproximou do maracatu. Quase todos tomaram conhecimento de sua existência por meio de amigos ou familiares que já participavam do grupo ou projeto, praticamente da mesma maneira que os jovens brancos de classe média das zonas mais nobres da cidade.

\section{O núcleo maranhense e a tradução das tradições}

Nos grupos do núcleo maranhense, tanto a questão da idade quanto a relação com a tradição é diferente da dos recriadores de 
maracatu. A média de idade dos componentes é bem mais alta; porém, por mais que a maioria não esteja na faixa etária considerada jovem, ou seja, de 15 a 25 anos, há, por assim dizer, uma extensão do estilo de vida juvenil, pois, nesse núcleo, como na esmagadora maioria dos grupos recriadores em geral, quase todos os participantes são solteiros. No Cupuaçu há pessoas de todas as faixas etárias, dos 13 aos 60 anos, sendo que uma segunda geração, de filhos dos participantes, já faz parte do grupo.

A grande diferença do núcleo maranhense em relação aos demais é que foi criado, ao menos em parte, por migrantes que já haviam tido a vivência dessas práticas culturais tradicionais - não da "verdadeira tradição", bem entendido. É importante perceber que essas tradições vão passando o tempo todo por inúmeras traduções. Elas são lidas e relidas, interpretadas e reinterpretadas, criadas e recriadas o tempo todo. O conceito de tradução da tradição, embora elaborado para outro contexto, o das migrações pós-coloniais, cabe para os artistas maranhenses estabelecidos em São Paulo, pois descreve, nas palavras de Stuart Hall (1997, p. 96), "pessoas que foram dispersadas para sempre de sua terra natal... [que] retêm fortes vínculos com seus lugares de origem e suas tradições, mas sem a ilusão de um retorno ao passado... [que são] obrigadas a negociar com as novas culturas onde vivem, sem simplesmente serem assimiladas por elas e sem perder completamente suas identidades".

Tudo começou com a vinda do músico e dançarino Tião Carvalho para São Paulo, nos anos 80. Como professor do curso de danças brasileiras do Teatro Vento Forte, ele despertou o interesse de seus alunos pelas expressões maranhenses e juntos fundaram o grupo Cupuaçu. Pouco depois, ele, suas alunas, alguns familiares, Graça Menezes, também maranhense, mais alguns conterrâneos e agregados paulistanos começaram a realizar numa praça em frente à casa do artista e líder do grupo, a festa maranhense de bumba meu boi. Procurando reproduzir todo o contexto ritual 
de São Luiz - ressurreição, batismo e morte do boi - a festa foi ganhando notoriedade, sobretudo entre os estudantes universitários, muitos dos quais integrantes dos próprios grupos recriadores de outras linhagens. Muitos jovens foram despertados para as culturas populares tradicionais pelo trabalho do Cupuaçu, os frequentadores da festa, os que passaram por suas diversas formações, os que fundaram seu próprio grupo.

É o caso do Pé no Terreiro, o único em franca atividade no pólo maranhense, em 2007, além do próprio Cupuaçu. Algumas de suas características permitem uma comparação bastante esclarecedora em relação aos grupos cujos participantes e líderes não têm nenhuma relação anterior com a tradição recriada. Do total dos participantes, $80 \%$ são negros, alguns migrantes de São Luiz do Maranhão, como o líder Henrique Menezes, e 70\% são filhos de migrantes dos Estados do Norte e Nordeste. Caso raro entre os grupos, onde existe um equilíbrio entre homens e mulheres, 90\% dos componentes são mulheres. Dentre elas, $70 \%$ fizeram ou fazem universidade e $60 \%$ trabalham como arte-educadoras. A grande diferença, se os comparamos aos recriadores de maracatu, reside, portanto, na cor, pertencimento étnico e local de nascimento próprio e dos pais. $\mathrm{O}$ grupo tem uma concentração muito maior de negros originários das Regiões Norte e Nordeste do país. Não é por acaso. Três dos fundadores são maranhenses e dois deles, os irmãos Henrique e Bartira são a nova geração da família Menezes, sobrinhos de Graça, Zezé e Dindinha, as Caixeiras do Divino da Casa Fanti-Ashanti de São Luiz do Maranhão. Vivenciam essas práticas culturais, na expressão de Téo Menezes, do grupo Beija Fulô, ao ser perguntado desde quando participava do grupo, desde a barriga da [sua] mãe.

Porém, ao contrário de seus ancestrais que tocavam, cantavam e dançavam por devoção ou brincadeira e da maioria dos recriadores que não tinham a vivência anterior da tradição, o Pé no Terreiro foi criado para ser um grupo profissional, para fazer espetáculos 
de danças maranhenses. Isto explica em parte a faixa etária mais elevada dos componentes deste grupo, cuja média fica em torno dos 30 anos de idade. É o caso também do Babado de Chita, não pertencente ao núcleo maranhense, mas cuja líder já conhecia as tradições de seu Estado natal. Embora até pouco tempo, o grupo tivesse dúvidas sobre seguir o caminho da profissionalização, Andréa Soares não pensava da mesma maneira. Pernambucana e formada em teatro, ao chegar a São Paulo percebeu imediatamente a existência de um nicho de mercado. Foi trabalhar na produção de Antonio Nóbrega e, em seguida, numa oficina de danças brasileiras na Casa de Cultura da Lapa, iniciou o grupo com seus alunos. Podese dizer que dentre os novos grupos, os migrantes, tenham vindo eles para São Paulo para se tornarem artistas ou não, percebem esta chance de profissionalização através da comercialização da tradição. Já os grupos de classe média, em geral, começam por diletantismo e, após algum tempo, ou se profissionalizam ou acabam enfrentando algum tipo de crise.

\section{A pesquisa e recriação das expressões sudestinas}

Os recriadores de manifestações sudestinas foram os mais difíceis de diagnosticar durante a pesquisa, indicando que pudessem estar passando por esse momento de crise, de transição, de substituição de componentes. Foram formados no interior da mancha por integrantes com um perfil semelhante ao dos recriadores de maracatu, mas, como os do núcleo maranhense, já não são tão jovens. Como vimos, em grande parte, sua matriz é o grupo Cachuera, hoje uma associação cultural com várias atividades. Uma delas era o grupo de danças, criado em 1996, não para fazer espetáculos, mas como uma forma de divulgar as pesquisas que vinham fazendo seus criadores Paulo Dias e Marcelo Manzatti, entre outros. Essas pesquisas abrangiam, sobretudo, o jongo e o batuque de umbigada, bem como o universo das congadas que inclui o moçambique, o 
ticumbi e algumas outras expressões que eles houveram por bem classificar como afro-sudestinas. Como o Abaçaí, o Cupuaçu e o Baque Bolado, também o Cachuera fez escola. Muita gente do meio passou pelo grupo. Mas a sua primeira formação mudou radicalmente em 2002 com a saída de Marcelo Manzatti e de muitos outros integrantes. O grupo de danças da Associação Cachuera se reformulou e continuou se apresentando, embora com muito menos frequência.

Parte dos componentes da primeira formação do Cachuera passou, após 2002, a se apresentar como Cambaiá em eventos culturais e como Moçambique de São Benedito em festas religiosas. Isto porque o grupo, formado por jovens paulistanos, ainda quando fazia parte do Cachuera, encontrara, numa de suas apresentações em frente à Igreja de Nossa Senhora do Rosário, no Largo do Paissandu, com o Mestre Sílvio de Oliveira, jovem migrante do Vale do Paraíba. Após a saída do Cachuera, vários componentes do Cambaiá dariam continuidade também ao trabalho ali iniciado, tomando parte da formação do grupo Sambaqui. Os dois grupos passaram a reunirse e a ensaiar na casa de Rosângela dos Santos, na Vila Pompéia, bairro situado entre Perdizes e Vila Madalena. O lugar era ideal para esses encontros, pois ficava, por assim dizer, no meio da mancha da cultura popular tradicional. É na mancha que tudo acontece. O líder do Cambaiá/Moçambique de São Benedito, por exemplo, Mestre Sílvio, embora seja mestre da tradição, fato singular entre os grupos recriadores, vem de Mogi das Cruzes, cidade da Grande São Paulo, para ensaiar no bairro de classe média. É ele que se desloca para encontrar os jovens de classe média e não o contrário. Em 2006, Rosângela dos Santos, líder do Sambaqui e contra-mestre do Cambaiá, teve que se mudar para a Brasilândia, bairro mais popular na Zona Norte de São Paulo. Os dois grupos ficaram sem um local fixo de ensaio, passando a reunir-se somente para apresentações.

Fatos como esses são esclarecedores sobre alguns dos limites da adesão dos jovens de classe média das grandes cidades às práticas 
tradicionais. A classe média paulistana vive em circuitos muito fechados e dificilmente se desloca para bairros mais afastados. Os grupos recriadores se apresentam, sim, na periferia da cidade, em festas populares no interior, escolas públicas, projetos sociais na periferia etc. Mas parecem não suportar por muito tempo a rotina de deslocar-se para regiões mais distantes.

\section{Os usos da tradição: a salvaguarda e a legitimidade}

No ano de 2002, Eder Rocha e alguns integrantes mais envolvidos com a recriação do maracatu em São Paulo começaram a se preocuparcom o futuro dos acontecimentos. Segundo o depoimento de Henrique Barros, o Capitão, líder do Batuntã, havia pessoas que faziam uma oficina e já fundavam um grupo de maracatu. Os líderes do movimento tiveram a sensação de que aquilo tudo estava fugindo do controle, a ponto de poder ameaçar a tradição e decidiram tomar algumas providências no sentido de resguardá-la. Agiram, para usar uma expressão de Anthony Giddens (1997), como guardiões da tradição. Segundo o autor, esta seria uma das funções básicas dos mestres, hoje tão cultuados por esses jovens, e não é por acaso que as iniciativas neste sentido foram tomadas por Eder Rocha. Na falta dos mestres mais antigos, diretamente ligados às nações de maracatu de Recife, ele representava a tradição entre os jovens paulistanos. Naquele momento, Eder Rocha encerra as atividades do seu grupo, o Olho da Rua, e começa a realizar os Encontros de Maracatu.

O primeiro Encontro de Pessoas que Trabalham com a Arte das Nações do Maracatu de Baque Virado aconteceu na Vila Madalena em 2002. No segundo, ocorrido em 2003, num sítio em Itu, interior de São Paulo, cerca de 300 participantes se encontraram com mestres de nações de maracatu de Recife. No ano seguinte, alguns desses mestres voltaram para o $3^{\circ}$ Encontro no Centro 
Cultural do Jabaquara, em São Paulo. Oficinas com os mestres se tornaram cada vez mais frequentes na cidade, ao mesmo tempo em que os integrantes dos grupos do Centro-Sul passam a realizar viagens para Recife com o intuito de vivenciar a tradição. Os que têm mais recursos financeiros, como os líderes da Cia. Caracaxá, Henrique Barros e Francisco Rojo, ficam até dois meses por ano em Recife, convivendo com as nações de maracatu. Tornam-se amigos dos mestres, trazem-nos para dar oficinas em São Paulo, hospedamnos em suas casas. Na metrópole, procuram transmitir aos demais essa experiência que, para eles, consiste em mostrar que o maracatu é muito mais do que ritmo, percussão, dança, música; é também uma tradição secular, de caráter religioso, preservada até hoje por pessoas muito pobres. Após esse contato com os mestres, em São Paulo ou em Recife, os líderes paulistanos passam por uma espécie de revelação ou de iniciação, demonstrando, a partir daí, um enorme respeito, uma reverência mesmo em relação à tradição. E, embora suas palavras vão se enfraquecendo do centro para a periferia dos grupos, não deixam de fazer suas admoestações aos presentes sobre o respeito à tradição, seja nos ensaios, como presenciamos no Ilê Aláfia, seja interrompendo uma "balada", como nos contou Henrique Barros, do Batuntã, quando um ou outro jovem mais animado ameaça derrubar cerveja numa alfaia.

Dentro dessa tendência mais arraigada à tradição, é criada, em 2003, a Cia. Caracaxá por alguns integrantes dos grupos Batuntã, Viralatisse e Baque Bolado reunidos para fazer uma apresentação de maracatu no Beco do Aprendiz. Enquanto os grupos de onde saíram os criadores são grupos fechados e profissionais, o Caracaxá é uma oficina aberta, não profissional. Enquanto o Batuntã e o Baque Bolado misturam uma série de manifestações tradicionais, o Viralatisse e o Caracaxá, são voltados para a pesquisa e a prática de uma única expressão cultural: o maracatu de baque virado. Enquanto 
o Batuntã faz a fusão do tradicional com o pop rock, usando todo tipo de instrumento, nos demais a ordem agora é tocar alfaia feita de macaíba, aro de jenipapo, corda de sisal e pele de cabra, como detalhou Jesum Biasim, do Baque Bolado.

O que se pode notar, afinal, nos discursos e práticas dos líderes dos grupos recriadores de maracatu é que o conhecimento da tradição e o contato com os mestres é motivo de orgulho para eles, revelado de forma clara durante as próprias entrevistas. Este contato se dá, em geral, nas oficinas que eles ministram nos Encontros de Maracatu, no Teatro Escola Brincante, na Associação Cultural Cachuera e em outros espaços ligados à cultura popular na cidade. Na apresentação dos grupos, seus líderes e integrantes, essas oficinas são sempre citadas, conferindo-lhes a mesma legitimidade que o diploma no meio escolar e científico. Já o contato mais íntimo com os mestres pode transferir até um certo carisma, como é o caso dos líderes dos grupos Caracaxá e Bloco de Pedra que os hospedam quando estão em São Paulo.

Quanto mais próximo se está da tradição, da raiz, maior a legitimidade (Bourdieu, 1989) entre os grupos recriadores. No centro, estão os mestres: eles irradiam a sabedoria. Alguns líderes convivem com eles; outros fizeram oficinas; outros, ainda, aprenderam com estes. Alguns grupos não tiveram contato direto com grupos tradicionais, nem mesmo seus líderes. Assim, a tradição - e, com ela, a legitimidade cultural - vai se enfraquecendo. Obviamente, sem que esta fosse a intenção dos agentes, a tradição tornou-se uma forma de hierarquização entre eles. E toda hierarquia gera privilégios: os grupos mais conhecidos e respeitados são chamados para apresentações no pequeno nicho de mercado encabeçado pela rede Sesc e, com um nome já consagrado, têm maior facilidade de ter um projeto aprovado ou ganhar um prêmio na área de política cultural. 


\section{Conclusão: uma relação intergeracional impactante, uma contradição de classe insolúvel}

Desde o seu surgimento no início do século XX, a noção de juventude esteve associada a características como instabilidade, rebeldia, delinquência. Até os anos 50, o debate concentrou-se nas áreas de Psicologia e Pedagogia, onde se buscavam as soluções para o pânico moral que tomava conta da sociedade ocidental (Passerini, 1996). Porém, na segunda metade do século, nos efervescentes anos 60 , os jovens aparecem como sujeitos da história por meio de uma série de movimentos de caráter político, notadamente o estudantil, como também se transformam em protagonistas da primeira cultura popular de caráter internacional e midiático, o pop. Isto se torna possível porque esta é, nos países ricos, em particular nos Estados Unidos, a primeira geração que recebe mesada dos pais, a primeira geração de consumidores jovens. A partir de então passam a circular pelo mundo vários estilos de cantar, dançar, vestir-se, divertirse que se fundem com culturas locais, dando origem a novos estilos de cantar, dançar, vestir-se, divertir-se, os quais, por sua vez, retroalimentam a indústria do pop - numa relação de forças, evidentemente, desigual. Desde então, a sociedade ocidental e as Ciências Sociais dedicam-se a entender o fenômeno juvenil do ponto de vista cultural, a partir de conceitos como subculturas, usado sobretudo pelos estudos ingleses, tribos urbanas, popularizado por Michel Maffesoli (1987) e, mais recentemente, culturas juvenis ou sociabilidade juvenil (Costa, Silva, 2006; Magnani, 2007). Quando os estudos se referem a realidades mais perversas como as dos jovens pobres e/ou ligados à violência, em geral, surgem os termos galeras e gangues (Guimarães, 1998; Zaluar, 2004). Na maioria dos estudos recentes busca-se enfatizar o aspecto cultural, a capacidade artística, a criatividade dos jovens mesmo nas condições econômicas mais difíceis, marca que se acentuou após as primeiras análises sobre o hip hop (Shusterman, 1998; Herschmann, 2000). Porém, de uma certa maneira, a noção de juventude nunca se livrou totalmente de sua 
marca de nascença, pelo menos de características como inconstância e nomadismo (Almeida, Tracy, 2003, entre outros).

Pode-se dizer que os jovens recriadores de culturas populares são nômades em busca de raízes. Perguntados sobre os motivos que os levaram a entrar para esses grupos, as alternativas eram: 1) Por nada, fui lá, gostei e fiquei; 2) Influência do(s) amigo(s); 3) Procurava algo diferente/alternativo; 4) Me interessava por culturas tradicionais; 5) Gostava de música, dança, percussão etc; 6) Busca de uma vivência comunitária; 7) Busca espiritual/religiosa. O respondente podia escolher até três delas.

Os participantes apontaram em massa as alternativas referentes ao "interesse por culturas tradicionais" e ao "gosto por música, dança e percussão". Num nível bem inferior, mas ainda expressivo, apareceu a "busca por uma vivência comunitária". Depois de entrar para o grupo, no entanto, as mudanças parecem ser bem maiores. Quase a totalidade dos jovens que respondeu aos questionários acredita que a participação no grupo mudou vários aspectos de sua vida: grande parte acha que modificou seu relacionamento com as pessoas em geral e uma parte um pouco menor acha que também modificou sua relação com os mais velhos; grande parte, ainda, pensa que alterou sua atitude para com a natureza e uma parte um pouco menor, também, para com o consumo; e, finalmente, boa parte disse que mudou suas convicções religiosas.

De fato, os grupos recriadores de culturas populares tradicionais podem formar grupos com um estilo de vida próprio (Bourdieu, 1989). ${ }^{2}$ Possuem uma maneira característica de se vestir: as moças usam roupa muito colorida, saia comprida, rodada, estampada, de chita, sandália rasteirinha ou sapatilha chinesa, colares de semente ou miçanga, flor no cabelo e brincos grandes, o que facilita e aumenta o efeito quando se dança um samba de roda, um tambor de crioula etc. Os rapazes gostam de andar de calças largas, feitas de 
sacos alvejados, e camisetas ou batas brancas, colares iguais aos das moças, tênis, cabelos dreads, faixas, alargador de orelha, parecido com o pessoal da capoeira, que é o mesmo do samba de roda, e, portanto, faz parte deste circuito. ${ }^{3}$ Seu lazer consiste basicamente em frequentar os próprios espaços do circuito: apresentações no Sesc de nomes como Siba, Nação Zumbi, de samba da Velha Guarda, ou shows, festas e eventos promovidos com mais frequência pelos grupos pioneiros: Abaçaí, Cachuera, Cupuaçu, Baque Bolado e sua já conhecida Baque Balada. Ou em encontrar-se uns com os outros. Quando isto acontece, cada um leva alguma coisa para comer e bebem cachaça, cerveja, refrigerante. Mas, acima de tudo, dançam muito e tocam muito, muito tambor.

Porém, o contato com os valores, crenças, costumes, personagens e, principalmente, com os próprios grupos de artistas populares, provoca em muitos deles mudanças mais profundas. Não se trata apenas de ir lá cantar e dançar. Não é pequeno, por exemplo, o número de participantes que, após entrar para um desses grupos, se inicia numa das religiões afro-brasileiras - sobretudo o candomblé-, às quais, como dissemos no início, quase todas essas práticas estão ligadas. Outros integrantes dos grupos incorporam às suas vidas práticas do catolicismo tradicional que, certamente, não faziam parte do seu universo cultural, como manter devoção aos santos e tudo o que daí decorre, acender velas, usar fitas e medalhas, fazer festas, pagar promessas. Os mais descrentes captam esta ambiência como uma espiritualidade ou uma energia diferente.

O estilo é próximo também de valores naturalistas, ecológicos e pacifistas. Daí certa mudança de atitude dos jovens para com a natureza e o consumo. Porém, a principal marca grupal, neste caso, é a que se refere a um dos valores mais rebaixados pela modernidade em comparação com as sociedades tradicionais: o respeito aos mais velhos. Em geral, os jovens são atraídos para os grupos, como é característico desta faixa etária, por amigos que já fazem parte deles. 
Esta foi a resposta obtida nos questionários, sobretudo os da Zona Oeste, onde estão os jovens de classe média. Na periferia, o papel dos familiares é maior, mas, por vezes, este familiar é um irmão ou primo, ou seja, da mesma faixa etária. Como vimos, exceto no caso do núcleo maranhense, a recriação de culturas populares por esses grupos juvenis em São Paulo nada tem a ver com tradição de família. Porém, uma vez no grupo, alguns jovens entrarão em contato, como vimos, com os mestres da tradição. E esta experiência, a julgar pela resposta aos questionários e os depoimentos colhidos, tem um impacto grande sobre suas vidas. Eles conseguem olhar os mais velhos de uma maneira nada habitual na sociedade moderna: como aqueles que têm mais experiência, mais conhecimento da vida e têm muitas coisas a ensinar.

Esse contato com os mestres e outros artistas populares mais velhos leva, muitas vezes, ao estabelecimento de uma relação afetiva entre eles. É o que pensa Vanessa Munhoz, antropóloga e participante dos grupos Cambaiá e Sambaqui (Munhoz, 2006). Esta é uma das características mais notáveis deste novo momento na história das apropriações das práticas denominadas de "culturas tradicionais" ou "cultura popular". Como antes, continua havendo uma apropriação estética dessas criações populares, mas, pela primeira vez, há, pelo menos, uma preocupação explícita com o artista e a sua condição de pobreza. Embora não saibam como resolvê-la, esta é uma questão que preocupa principalmente os líderes e integrantes mais antigos e comprometidos dos grupos recriadores: como recompensar os grupos tradicionais pelo repertório que aprendem com eles? O problema tem até um nome entre eles: o retorno para a comunidade. Mas não tem solução. Há grupos que mandam a fita gravada com a "comunidade"; um deles separa uma pequena parte do cachê. Eventos culturais são realizados para angariar fundos para um artista ou grupo tradicional passando por maiores dificuldades. Trazê-los para apresentações em São Paulo é bom, mais pela viagem do que pelos ganhos porque, 
financeiramente, não compensa. A vontade de ajudar não adianta: o que os separa não é a diferença de idade, mas a diferença de classe, impossível de resolver sem transformar o sistema capitalista.

E uma das maiores forças do sistema na contemporaneidade é o movimento, a excitação, o frenesi, o espetáculo. As culturas tradicionais não teriam chance de sobreviver no mundo de hoje se não oferecessem elementos que as conectassem com a modernidade. Como vimos, lado a lado como "interesse pelas culturas tradicionais", os jovens pesquisados revelaram seu gosto por "música, dança e percussão". De fato, o ritmo frenético dos tambores parece ser o que mais atrai os jovens para participarem desses grupos.

Que os jovens de classe média estejam interessados no aspecto lúdico das culturas tradicionais não é de se estranhar. Afinal, o entretenimento, ao lado do consumo, é o denominador comum da sociedade contemporânea. A questão é: isto não estaria acontecendo também com os jovens das classes populares? Vários estudos já demonstraram que nesta faixa etária a busca por diversão e evasão se acentua mais ainda, independentemente de outros recortes sociais (Mira, 2001). O problema que se coloca para as culturas populares tradicionais é que se assiste hoje a uma inversão: alguns jovens de classe média, dotados de um capital cultural distintivo, conseguem conjugar diversão com o que os eruditos consideram uma cultura legítima, as tradições populares, enquanto a esmagadora maioria dos jovens das classes populares prefere as "diversões baratas" que se desenvolvem nas periferias das grandes cidades, a cultura popular de massa. Mais do que isto, e o que realmente ameaça a sobrevivência das tradições populares, é que muitos jovens já não são mais devotos como seus pais ou avós. Seja porque a sociedade moderna, por seus próprios princípios, se afasta da religião, cultua o consumo e o entretenimento, seja porque, há algumas décadas, o catolicismo tradicional vem perdendo terreno para as religiões evangélicas ou para as tendências católicas carismáticas, ambas 
avessas às festas populares. Sem a devoção das novas gerações, o último elo de transmissão das tradições populares se romperia.

No entanto, há vários testemunhos e evidências de que jovens das classes populares estão voltando a valorizar práticas culturais que, por vezes, estavam dentro de sua casa, depois de terem visto outros jovens de classe média, da cidade grande, irem lá dançar, tocar e cantar com seus pais ou avós. O recente interesse pelas culturas populares tem levado à reconstituição de vários grupos tradicionais que estavam inativos e para isto a participação dos mais jovens tem sido essencial. Grupos infantis também têm sido criados. É como se a cultura popular tradicional estivesse renascendo. E os planos de salvaguarda - com seus registros e prêmios - os encontros e festivais de culturas tradicionais e algumas outras iniciativas têm contribuído para que isto aconteça porque valorizam, abrem espaços de apresentação e, por vezes, oferecem condições materiais, ainda que precárias e temporárias, para a subsistência dos grupos tradicionais.

Porém, é preciso notar: a valorização, a legitimação vem de fora e vem de cima. Diferentemente do que acontece com outras práticas que seguiram o caminho da auto-afirmação como, por exemplo, os grupos afro mais ligados à produção cultural baiana que souberam se renomear como "cultura e arte negra", aquelas que permaneceram reunidas sob o rótulo de "folclore" ou "cultura popular" não tiveram muita força para se legitimar. De meados do século XX para cá, nem aos olhos das novas gerações porque se a escola deixa inúmeras lacunas ao tentar impor a cultura erudita, os meios de comunicação de massa não falham, estão por toda parte a seduzir e legitimar o prazer do consumo e do entretenimento. Portanto, talvez esta seja a única recompensa que os jovens de classe média possam oferecer aos detentores dessas práticas tradicionais: mais um reconhecimento da sua importância, seja como "cultura brasileira", seja como "cultura popular". 


\title{
Notas
}

1 Vários jovens pertencem a mais de um grupo: o Viralatisse que é o grupo responsável pelo Bloco de Pedra, o próprio Bloco de Pedra e a Cia. Caracaxá. No entanto, para a elaboração dos dados, as informações prestadas por pessoa só foram computadas uma vez. No total foram 33 questionários respondidos.

2 Utilizo o conceito de Pierre Bourdieu, embora reconheça seus limites históricos. Creio tornar-se cada vez mais imprópria a ideia de que uma dimensão do estilo de vida é capaz de revelar todas as demais.

3 Não me refiro aqui à capoeira praticada em academias, evidentemente. Durante a pesquisa visitamos também dois grupos de capoeira, o 'Nzinga de Capoeira Angola e o Mestre Ananias, os quais não estou considerando aqui devido à complexidade do tema e à exiguidade do espaço.

Youth sociability and traditional cultural practices in São Paulo city

\begin{abstract}
The aim of this text is to present part of the results of the collective research performed in 2007 in Pontifícia Universidade Católica de São Paulo (Pontifical Catholic University of São Paulo). The investigation studied eighteen groups involved with the "recreation" of the Brazilian popular traditions in São Paulo city, trying to discern the specificities determined by the history of expressions spoken in Maranhão, Pernambuco and in Southeast as well as the people who recreated those expressions at the metropolis, many of them being middle class, young people, and of the circuit of sociability, culture and leisure they are associated with. Based on this pratices, their agents and their representations, the article develops a brief reflection about the uses of "tradition" and its impact in the life of these young people.
\end{abstract}

Keywords: tradition; popular culture; youth; urban culture. 


\section{Referências bibliográficas}

ABREU, Martha. O império do Divino: festas religiosas e cultura popular no Rio de Janeiro, 1830-1900. Rio de Janeiro: Nova Fronteira; São Paulo: Fapesp, 1999.

ANDRADE, Mário de. Danças dramáticas do Brasil. 2. ed. Belo Horizonte: Itatiaia; Brasília: INL, Fundação Pró-Memória, 1982. 3 v.

ALMEIDA, M. Isabel M. de; TRACY, Kátia M. de Almeida. Noite nômades: espaço e subjetividade nas culturas jovens contemporâneas. Rio de Janeiro: Rocco, 2003.

BASTIDE, Roger. As religiões africanas no Brasil: contribuição a uma sociologia das interpenetrações de civilizações. São Paulo: Edusp, Pioneira, 1971.

BOURDIEU, Pierre. La distinción: critérios y bases sociales del gusto. Madri: Taurus, 1989.

COSTA, Márcia Regina da; SILVA, Elisabeth Murilho da. Sociabilidade juvenil e cultura urbana. São Paulo: Educ, 2006.

DEL PRIORI, Mary. Festas e utopias no Brasil colonial. São Paulo: Brasiliense, 1994.

FRÚGOLI JR., Heitor. Sociabilidade urbana. Rio de Janeiro: Zahar, 2007.

GIDDENS, Anthony. A vida em uma sociedade pós-tradicional. In: BECK, U.; GIDDENS, A.; Lash S. Modernidade reflexiva: política, tradição e estética na ordem social moderna. São Paulo: Ed. Unesp, 1997.

GUIMARÃES, Eloísa. Escola, galeras e narcotráfico. Rio de Janeiro: Ed. UFRJ, 1998.

HALBWACKS, Maurice. A memória coletiva. São Paulo: Vértice, Ed. Revista dos Tribunais, 1990.

HALL, Stuart.1 A identidade cultural na pós-modernidade. Rio de Janeiro: DP\&A, 997. 
HERSCHMANN, Micael. O funk e o hip hop invadem a cena. Rio de Janeiro. Ed. UFRJ, 2000.

JANCSÓ, István; KANTOR, Iris (Orgs.). Festa: cultura e sociabilidade na América portuguesa. São Paulo: Hucitec, 2002. 2 v.

MAFFESOLI, Michel. O tempo das tribos: o declínio do individualismo nas sociedades de massa. Rio de Janeiro: Forense-Universitária, 1987.

MAGNANI, José Guilherme C. Quando o campo é a cidade: fazendo Antropologia na metrópole. In: MAGNANI, José Guilherme C.; TORRES, Lílian de Lucca (Orgs.) Na metrópole: textos de Antropologia Urbana. São Paulo: Edusp, Fapesp, 2000.

MAGNANI, José Guilherme C.; SOUZA, Bruna Mantese de (Orgs). Jovens na metrópole: etnografias de circuitos de lazer, encontro e sociabilidade. São Paulo: Terceiro Nome, 2007.

MIRA, Maria Celeste. Ongueiros, festeiros e simpatizantes: o circuito urbano da cultura popular em São Paulo. In: FRÚGOLI JR., Heitor; PEIXOTO, Fernanda; ANDRADE, Luciana T. (Orgs.). As cidades e seus agentes: práticas e representações. São Paulo: Edusp; Belo Horizonte: Ed. PUC Minas, 2006.

- Pop e bizz: adolescência, juventude e mercado editorial. In: . O leitor e a banca de revistas: a segmentação da cultura no século XX. São Paulo: Olho D’Água, Fapesp, 2001.

MORIN, Edgar. Juventude. In: . Cultura de massas no século XX: o espírito do tempo. 3. ed. Rio de Janeiro: Forense-Universitária, 1975. v.1.

MUNHOZ, Vanessa. Diálogos na atualidade: cultura popular e imprensa: aspectos do interesse atual pelas práticas culturais populares. 2002. Trabalho de conclusão de curso (Especialização em Jornalismo Cultural) - Pontifícia Universidade Católica de São Paulo (PUCSP), 2002.

. "Nóis somo irmão congueiro": estudo sobre congadas no século XXI em São Paulo. 2006. Dissertação (Mestrado em Ciências 
Sociais) - Pontifícia Universidade Católica de São Paulo (PUC-SP), 2006.

ORTIZ, Renato. Cultura popular: românticos e folcloristas. São Paulo: Olho D’Água, 1992.

PASSERINI, Luisa. A juventude: metáfora da mudança social. Dois debates sobre os jovens: a Itália fascista e os Estados Unidos da década de 1950. In: LEVI, Giovani; SCHMITT, Jean-Claude (Orgs). História dos jovens 2: da época contemporânea. São Paulo: Cia das Letras, 1996. p. 319-382.

SHUSTERMAN, Richard. Vivendo a arte: o pensamento pragmatista e a estética popular. São Paulo: Ed. 34, 1998.

SIMMEL, Georg. Questões fundamentais da Sociologia. Rio de Janeiro: Zahar, 2006.

SQUEFF, Enio. Vila Madalena: crônica histórica e sentimental. São Paulo: Boitempo, 2002,

SOUZA, Marina de Mello e. Reis negros no Brasil escravista: história da festa de coroação de Rei Congo. Belo Horizonte: Ed. UFMG, 2002.

TABOADA, Cynthia Elias. Cultura tradicional e pós-modernidade: estudo do resgate de danças e folguedos tradicionais na cidade de São Paulo. Relatório final de bolsa de iniciação científica da Fapesp, Instituto de Artes da Unesp, orientador Alberto Ikeda. 2000. [Não publicado].

TINHORÃO, José Ramos. As festas no Brasil colonial. São Paulo: Ed. 34, 2000.

WILLIAMS, Raymond. Marxismo y literatura. Barcelona: Península, 1984.

ZALUAR, Alba. Gangues, galeras e quadrilhas: globalização, juventude e violência. In: . Integração perversa: pobreza e tráfico de drogas. Rio de Janeiro: Editora FGV, 2004. 